\title{
Bacteriemia após exodontia unitária, empregando dois métodos de anti-sepsia intrabucal
}

\section{Bacteremia following dental extraction and two methods of intra-oral antisepsis}

\author{
Valdemar Mallet da ROCHA BARROS* \\ Izabel Yoko ITO** \\ Rosa Vitória P. AZEVEDO** \\ Danielle MORELLO*** \\ Pedro Augusto ROSATELI ${ }^{* * * * *}$ \\ Lara Cappato FILIPECKI ${ }^{* * * *}$
}
ROCHA BARROS, V. M.; ITO, I. Y.; AZEVEDO, R. V. P.; MORELLO, D.; ROSATELI, P. A.; FILIPECKI, L. C. Bacteriemia após exodontia unitária, empregando dois métodos de anti-sepsia intrabucal. Pesq Odont Bras, v. 14, n. 1, p. 19-24, jan./mar. 2000.

\begin{abstract}
O objetivo do trabalho foi avaliar a freqüência de bacteriemias pós-exodontia utilizando dois métodos de anti-sepsia pré-operatória, identificando os microrganismos isolados de hemoculturas pós-extração e avaliando a sua suscetibilidade a antibióticos. Vinte e seis pacientes tiveram 33 dentes extraídos. Dezesseis casos foram submetidos a anti-sepsia com bochecho com $15 \mathrm{ml}$ de gluconato de clorexidina a $0,12 \%$ por um minuto, seguido da fricção das faces dentais com cotonete embebido na mesma solução (método 1) e 17 à anti-sepsia com dois bochechos com $15 \mathrm{ml}$ de cloreto de cetilpiridinio a 1:4.000 por um minuto, intercalados pela fricção das faces dentais com peróxido de hidrogênio a 3,0\% (método 2). Previamente à extração dental e cerca de 1 a 3 minutos após a mesma, colhiam-se 5,0 ml de sangue que eram semeados em meios de cultura e incubados por 20 dias. As cepas provenientes de hemoculturas positivas foram identificadas e submetidas ao antibiograma. Do total de casos, $68,8 \%$ apresentaram hemocultura positiva para o método 1 e 70,6\% para o método 2. Houve maior prevalência de Actinomyces nos dois métodos, seguido de Streptococcus, Staphylococcus e Peptostreptococcus. O maior indice de resistência aos antibióticos testados esteve relacionado à oxacilina, enquanto não foi observada nenhuma cepa resistente à amoxicilina ou à cefalotina. Conclui-se que a freqüência de bacteriemia pós-exodontia foi elevada, independentemente do método de anti-sepsia empregado, prevalecendo microrganismos anaeróbios, os quais foram mais suscetiveis a amoxicilina e a cefalotina.
\end{abstract}

UNITERMOS: Anti-sépticos bucais; Antibióticos.

\section{INTRODUÇÃO}

Admite-se atualmente, que bacteriemia após procedimentos odontológicos invasivos, como a extração dental, possa ocorrer em $100,0 \%$ dos ca $\operatorname{sos}^{12,15}$, tendo sua freqüência aumentada em decorrência de alguns fatores como presença de processo inflamatório, idade do paciente, tempo de duração da cirurgia e volume de sangue perdido durante este procedimento. Essas bacteriemias são transitórias, assintomáticas, de curta duração e não têm significado clínico importante em indivíduos normais, pois o inóculo é pequeno e a virulência dos microrganismos envolvidos é baixa. No entanto, episódios recorrentes de bacteriemia po- dem representar, em pacientes com cardiopatias predisponentes, um risco cumulativo de endocardite infecciosa. Bacteriemia transitória, adesão de microrganismos às válvulas cardíacas e a formação de vegetações de bactérias são reconhecidos como fatores fundamentais na patogênese da endocardite infecciosa.

JASPER; LITTLE ${ }^{14}$ (1984) relataram que diversos levantamentos indicam que mais de $92 \%$ dos casos de endocardite infecciosa podem ser de origem dental.

Os estreptococos são os microrganismos mais freqüentemente envolvidos em endocardite infecciosa, sendo os responsáveis pela maior parte dos

\footnotetext{
* Professor da Faculdade de Odontologia da Universidade de São Paulo - Ribeirão Preto.

** Professores da Faculdade de Ciências Farmacêuticas da Universidade de São Paulo - Ribeirão Preto.

*** Bolsista de Aperfeiçoamento; **** Bolsistas de Iniciação Científica - CNPq.
} 
ROCHA BARROS, V. M.; ITO, I. Y.; AZEVEDO, R. V. P.; MORELLO, D.; ROSATELI, P. A.; FILIPECKI, L. C. Bacteriemia após exodontia unitária, empregando dois métodos de anti-sepsia intrabucal. Pesq Odont Bras, v. 14, n. 1, p. 19-24, jan./mar. 2000.

casos que se seguem a tratamentos odontológi $\cos ^{18}$. Esses microrganismos apresentam grande aderência ao endotélio das válvulas cardiacas ${ }^{10}$ ou às vegetações estéreis formadas por plaquetas e fibrina, nas quais acredita-se tem início a doença ${ }^{1}$. NORD; HEIMDAHL ${ }^{20}$ (1990) consideram a produção do dextrano pelos $S$. sanguis e $S$. mutans como fator de virulência na patogênese da endocardite infecciosa.

MOORE et al. ${ }^{19}$ (1982), ao avaliarem 500 pacientes com endocardite bacteriana subaguda, isolaram em $208(41,6 \%)$ casos S. sanguis e, em 35 $(7,0 \%)$ S. mutans, sugerindo que esses microrganismos eram provenientes da cavidade bucal. Esses microrganismos se aderem mais facilmente à superfície do coração do que outros, especialmente, porque são capazes de produzir um polissacarídeo extracelular, o dextrano.

Em uma análise de 28 episódios de endocardite infecciosa Furini et al. ${ }^{9}$ (1993), em pacientes internados em um hospital universitário, encontraram estreptococos viridans representando $35,0 \%$ dos microrganismos isolados, $50,0 \%$ dos gram-positivos e $75,0 \%$ dos estreptococos.

MACFARLANE et al. ${ }^{17}$ (1984) partilham da opinião de que a redução do número de bactérias da cavidade oral pelo uso de anti-sépticos diminui a probabilidade de bacteriemia durante tratamento odontológico. Esta diminuição é importante em todos os casos de procedimentos invasivos, uma vez que, nem todos os pacientes de risco para endocardite infecciosa são identificados previamente à realização desses procedimentos.

Com base nas considerações apresentadas, nos propusemos a avaliar a freqüência de bacteriemia após exodontia unitária, quando precedida de anti-sepsia intrabucal por bochecho e fricção dos dentes; identificar os microrganismos presentes nas bacteriemias pós-exodontias e avaliar a suscetibilidade a alguns antibióticos dos microrganismos isolados de hemoculturas.

\section{MATERIAIS E MÉTODOS}

Participaram desse estudo 26 pacientes, os quais foram separados em dois grupos, de acordo com o método de anti-sepsia utilizado, e tiveram 33 dentes extraídos.

Dezesseis casos de exodontias foram submetidos à anti-sepsia intrabucal pré-operatória empregando um bochecho com 15,0 $\mathrm{ml}$ de gluconato de clorexidina a 0,12\% (Periogard - Colgate Palmolive Ltda, SP) durante 1 minuto, seguido da fricção das faces dentais com cotonete embebido na mesma solução (método 1) e 17 casos foram submetidos a dois bochechos com 15,0 ml de cloreto de cetilpiridínio a 1:4.000 (Cepacol - Merrell Lepetit Farmacêutica Ltda, SP) durante 1 minuto, intercalados pela limpeza das faces dentais com um cotonete embebido em peróxido de hidrogênio a 3,0\% (método 2). Os pacientes com indicação de extração de mais de um dente, participaram duas vezes do trabalho, cada qual empregando um método diferente de anti-sepsia. Nesses casos respeitou-se um intervalo de, pelo menos, duas semanas entre as duas intervenções cirúrgicas.

Em todos os pacientes, após a anti-sepsia da fossa ante cubital, foram coletados $5,0 \mathrm{ml}$ de sangue venoso da veia ante cubital antes e 1 a 3 minutos após a extração dental, sempre antes da toalete do alvéolo dental e da sutura, e imediatamente transferidos para frascos contendo $100,0 \mathrm{ml}$ do meio de cultura Tio's (caldo tioglicolato sem dextrose e sem indicador - Difco, hermeticamente vedado com rolha de borracha). Os frascos foram colocados em estufa a $37^{\circ} \mathrm{C}$, durante 20 dias, e observados a cada 48 horas, com a finalidade de verificar crescimento bacteriano. A cada 48 horas, dos frascos que apresentavam turvação ou suspeita de crescimento bacteriano, foram feitos esfregaços em lâminas, que eram a seguir submetidos à coloração de Gram e examinados microscopicamente, utilizando microscópio óptico comum. Constatado o crescimento microbiano, eram feitos repiques nos meios de cultura ágar mitis salivarius (Ms) e ágar sacarose bacitracina $\left(\mathrm{SB}_{20}\right)$, incubados em microaerofilia pelo sistema chama de vela, ágar gema de ovo (Ni) e ágar MacConkey (MC) em aerobiose, e ágar sangue (As) em anaerobiose pelo sistema GasPak. As hemoculturas foram consideradas negativas, quando decorridos 20 dias de observação não se evidenciavam microrganismos em repiques e nem nas análises microscópicas.

As intervenções cirúrgicas foram iniciadas cerca de quinze minutos após o término da anti-sepsia empregando a técnica de fórcipe auxiliada por elevadores.

A caracterização dos gêneros dos microrganismos isolados das hemoculturas foi realizada pela observação das características morfológicas, tintoriais e bioquímicas. Os Streptococcus foram identificados baseados nos esquemas propostos por BEIGHTON et al. ${ }^{3,4}(1991,1994)$ e $\operatorname{RUOFF}^{21}$ (1995), enquanto que os pertencentes ao gênero Peptostreptococcus e Actinomyces de acordo com HILLIER; MONCLA ${ }^{13}$ (1995) e os Staphylococcus 
ROCHA BARROS, V. M.; ITO, I. Y.; AZEVEDO, R. V. P.; MORELLO, D.; ROSATELI, P. A.; FILIPECKI, L. C. Bacteriemia após exodontia unitária, empregando dois métodos de anti-sepsia intrabucal. Pesq Odont Bras, v. 14, n. 1, p. 19-24, jan./mar. 2000.

segundo BLUM; RODVOLD ${ }^{6}$ (1987). As cepas de microrganismos isolados de hemoculturas, obtidas após a extração dental foram submetidas a prova de suscetibilidade aos antibióticos pela técnica de Kirby-Bauer de difusão em ágar, empregando-se discos impregnados com concentração única de antibiótico. Os discos de antibióticos eram de procedência Difco e apresentavam a potência: amoxicilina $30 \mu \mathrm{g}$; cloranfenicol $30 \mu \mathrm{g}$; eritromicina $15 \mu \mathrm{g}$, oxacilina $1 \mu \mathrm{g}$ e tetraciclina $30 \mu \mathrm{g}$. Após a aplicação dos discos as placas foram incubadas dentro de 15 minutos obedecendo o tipo respiratório de microrganismos como preconizado por WOODS; WASHINGTON ${ }^{26}$ (1995) e WEXLER; DOERN $^{25}$ (1995).

\section{RESULTADOS E DISCUSSÃO}

Das 35 coletas de sangue realizadas previamente à anti-sepsia intrabucal, duas apresentaram hemoculturas positivas e, por essa razão, os respectivos casos foram eliminados. Assim, a amostra final constou de 33 casos, tendo sido 16 tratados pelo método 1 de anti-sepsia e 17 pelo método 2 (Tabela 1).

Os dois métodos de anti-sepsia empregados apresentaram resultado semelhante no tocante à incidência de bacteriemia pós-exodontia.

Os resultados deste trabalho comprovam a alta freqüência de bacteriemia pós-exodontia e demonstram a necessidade da associação de medidas locais de anti-sepsia à profilaxia antibiótica, instituída previamente à realização da extração dental, principalmente, nos pacientes com risco de endocardite infecciosa.

Esta afirmação está de acordo com o que tem sido enfatizado por diversos autores, acerca do valor da associação da degermação da boca por meio do enxágüe com antimicrobianos com a profilaxia antibiótica em pacientes com risco de endocardite infecciosa ${ }^{5,7,23}$.

Nas hemoculturas foram identificados microrganismos dos gêneros Actinomyces (47,8\%), Streptococcus $(26,1 \%)$, Peptostreptococcus $(4,3 \%)$ e

TABELA 1 - Resultados das 33 hemoculturas pós-exodontias precedidas por anti-sepsia intrabucal pelo método 1 ou 2 .

\begin{tabular}{l|c|c|c|c|c|c}
\hline \hline \multirow{2}{*}{ Hemocultura } & \multicolumn{2}{|c|}{ Método 1 } & \multicolumn{2}{c|}{ Método 2 } & \multicolumn{2}{c}{ Total } \\
\cline { 2 - 7 } & $n^{\circ}$ casos & $\%$ & $n^{\circ}$ casos & $\%$ & $n^{\circ}$ casos & $\%$ \\
\hline Positiva & 11 & 68,8 & 12 & 70,6 & 23 & 69,7 \\
\hline Negativa & 5 & 31,2 & 5 & 29,4 & 10 & 30,3 \\
\hline \hline
\end{tabular}

Staphylococcus $(17,4 \%)$. Na Tabela 2 são apresentados os gêneros de microrganismos isolados nas hemoculturas e sua distribuição de acordo com o método de anti-sepsia empregado.

No presente trabalho, predominaram nas hemoculturas microrganismos anaeróbios do gênero Actinomyces, contrariando os relatos de diversos autores, que atribuem maior participação dos estreptococos nas bacteriemias de origem dental. Estes resultados estão, em parte, de acordo com aqueles de HALL et al. ${ }^{11}$ (1993) que relataram que microrganismos anaeróbios foram isolados de bacteriemia duas vezes mais freqüentemente que cepas aeróbias. Esses autores isolaram microrganismos das espécies Actinomyces, Peptostreptococcus e Veillonella em pacientes com bacteriemia por anaeróbios.

De acordo com EVALDSON et al. ${ }^{8}$ (1982), a presença de bacteriemias pós-exodontias nas quais prevalecem microrganismos anaeróbios reflete a microbiota oral normal na área da cirurgia. Esta afirmação está de acordo com relatos de SHANSON et $a .^{22}$ (1978) e BALTCH et al. ${ }^{2}$ (1982).

Neste trabalho, estreptococos foram isolados em seis casos, diminuindo assim a freqüência de bacteriemias mais graves e potencialmente perigosas para pacientes com risco de endocardite infecciosa, uma vez que esses microrganismos têm sido os mais freqüentemente envolvidos com endocardite infecciosa que se seguem a tratamentos odontológicos ${ }^{18}$.

Admite-se que a redução do número de estreptococos no sulco gengival, obtida com o emprego da anti-sepsia intrabucal, constitui-se em um recurso importante na prevenção de endocardite infecciosa, pois ela provoca a diminuição de sua freqüência nas bacteriemias pós-exodontias.

TABELA 2 - Distribuição dos gêneros de microrganismos isolados nas 23 hemoculturas pós-exodontia de pacientes submetidos à anti-sepsia pelo método 1 ou 2 .

\begin{tabular}{l|r|r|r|r|r|r}
\hline \hline \multirow{2}{*}{$\begin{array}{c}\text { Gênero dos } \\
\text { microrganismos }\end{array}$} & \multicolumn{2}{|c|}{$\begin{array}{c}\text { Método 1 } \\
(11)\end{array}$} & \multicolumn{2}{c|}{$\begin{array}{c}\text { Método } 2 \\
(12)\end{array}$} & \multicolumn{2}{c}{ Total (23) } \\
\cline { 2 - 7 } & $\begin{array}{c}\mathrm{n}^{\circ} \\
\text { casos }\end{array}$ & $\%$ & $\begin{array}{c}\mathrm{n}^{\circ} \\
\text { casos }\end{array}$ & $\%$ & $\begin{array}{c}\mathrm{n}^{\circ} \\
\text { casos }\end{array}$ & $\%$ \\
\hline Actinomyces & 5 & 45,5 & 6 & 50,0 & 11 & 47,8 \\
\hline Streptococcus & 2 & 18,2 & 4 & 33,3 & 6 & 26,1 \\
\hline Peptostreptococcus & 1 & 9,1 & 0 & 0 & 1 & 4,3 \\
\hline Staphylococcus & 3 & 27,3 & 1 & 8,3 & 4 & 17,4 \\
\hline Não identificados & 3 & 27,3 & 2 & 16,7 & 5 & 21,7 \\
\hline \hline
\end{tabular}


ROCHA BARROS, V. M.; ITO, I. Y.; AZEVEDO, R. V. P.; MORELLO, D.; ROSATELI, P. A.; FILIPECKI, L. C. Bacteriemia após exodontia unitária, empregando dois métodos de anti-sepsia intrabucal. Pesq Odont Bras, v. 14, n. 1, p. 19-24, jan./mar. 2000.

Os resultados obtidos neste trabalho mostram que a bacteriemia pelos microrganismos do gênero Streptococcus ocorreu em 18,2\% dos casos, em que foi empregado um bochecho com clorexidina associada à limpeza das faces dentais com essa mesma solução (método 1), enquanto que com o emprego de dois bochechos com cloreto de cetilpiridínio intercalados com a limpeza das faces dentais com peróxido de hidrogênio a 3,0\% (método 2), ela ocorreu em 33,3\% deles. Com os Staphylococcus ocorreu o contrário, isto é, eles foram isolados em $27,3 \%$ dos casos em que foi empregado o método 1 de anti-sepsia e em 8,3\% pelo método 2 .

Das 23 hemoculturas positivas obtidas após a extração dental, foi possivel a identificação dos microrganismos em 18 (78,3\%) delas. Dessas, em 14 $(77,8 \%)$ hemoculturas foram isolados apenas microrganismos de um único gênero. Em 8 hemoculturas foi isolado apenas Actinomyces, em 4, Streptococcus e em duas delas, Staphylococcus. Nas outras $4(22,2 \%)$ foram isolados microrganismos de dois gêneros. Em um caso foi isolado Actinomyces e Streptococcus, em um Actinomyces e Staphylococcus, em um Staphylococcus e Streptococcus e no restante Peptostreptococcus e Actinomyces.

Entre a gama de antibióticos disponiveis foram selecionados: amoxicilina e eritromicina, em virtude de serem os antimicrobianos recomendados para a profilaxia de endocardite bacteriana em pa-

TABELA 3 - Distribuição das espécies de microrganismos isolados nas 23 hemoculturas pós-exodontia de pacientes submetidos à anti-sepsia pelo método 1 ou 2 .

\begin{tabular}{l|c|c}
\hline \hline \multicolumn{1}{c|}{ Microrganismos } & $\begin{array}{c}\text { Método 1 } \\
\left(\mathrm{n}^{\circ} \text { casos }\right)\end{array}$ & $\begin{array}{c}\text { Método 2 } \\
\left(\mathrm{n}^{\circ} \text { casos }\right)\end{array}$ \\
\hline A. bovis & 2 & 1 \\
\hline A. meyerii & 1 & 0 \\
\hline A. naeslundii & 1 & 3 \\
\hline A. odontolyticus & 0 & 2 \\
\hline A. viscosus & 2 & 2 \\
\hline St. gordonii biovar 1 & 0 & 2 \\
\hline St. mitis biovar 2 & 1 & 1 \\
\hline St. oralis & 0 & 1 \\
\hline St. sanguis biovar 1 & 1 & 1 \\
\hline St. sanguis biovar 2 & 0 & 0 \\
\hline Peptostreptococcus micros & 1 & 1 \\
\hline S. epidermidis & 3 & \\
\hline \hline
\end{tabular}

cientes de risco, e a oxacilina com o objetivo de detectar os microrganismos meticilino-resistentes. Quanto ao emprego da tetraciclina, por ser o agente freqüentemente utilizado na Odontologia para o tratamento de doenças periodontais e o cloranfenicol recomendado como terceira opção em pacientes com problema de hipersensibilidade aos antibióticos do grupo das penicilinas e cefalosporinas.

Os resultados dos antibiogramas revelaram baixa freqüência de cepas resistentes aos antibióticos testados. A distribuição dos microrganismos de acordo com as espécies pode ser observada na Tabela 3.

Os microrganismos do gênero Actinomyces, de maior ocorrência, mostraram-se suscetiveis à amoxicilina, ao cloranfenicol, à cefalotina, à eritromicina e à tetraciclina, tendo sido encontrada apenas uma cepa resistente à oxacilina. O maior índice de resistência esteve relacionado à oxacilina, com quatro cepas, uma destas (St. gordonii biovar 1) resistente também à tetraciclina.

A distribuição dos microrganismos resistentes aos antibióticos, isolados de hemoculturas pós-exodontia, considerando os resultados intermediários como resistentes, encontra-se na Tabela 4.

Os resultados do presente trabalho estão em desacordo com os de LEVINER et al. ${ }^{16}$ (1984), que sugerem que microrganismos resistentes à penicilina constituem parte da microbiota oral em pelo menos $7,0 \%$ da população normal, sendo este índice provavelmente maior em indivíduos com contatos freqüentes com antibióticos.

Os indices diferentes de resistência ou de suscetibilidade aos antibióticos encontrados nos diversos trabalhos, provavelmente resultaram de diferenças de origem das cepas, da metodologia de

TABELA 4 - Distribuição dos microrganismos resistentes a antibióticos isolados de hemoculturas pós-exodontia de pacientes submetidos à anti-sepsia pelo método 1 ou 2.

\begin{tabular}{l|c|c|c}
\hline \hline \multicolumn{1}{c|}{ Microrganismos } & $\begin{array}{l}\text { Método 1 } \\
\left(\mathrm{n}^{\circ} \text { casos }\right)\end{array}$ & $\begin{array}{c}\text { Método 2 } \\
\left(\mathrm{n}^{\mathrm{o}} \text { casos }\right)\end{array}$ & Antibiótico \\
\hline A. odontolyticcus & 0 & 1 & Oxacilina \\
\hline St. gordonii biovar 1 & 0 & 1 & $\begin{array}{c}\text { Oxacilina } \\
\text { Tetraciclina }\end{array}$ \\
\hline St. mitis biovar 2 & 0 & 1 & Oxacilina \\
\hline St. oralis & 0 & 1 & Oxacilina \\
\hline S. epidermidis & 1 & 0 & Eritromicina \\
\hline \hline
\end{tabular}


ROCHA BARROS, V. M.; ITO, I. Y.; AZEVEDO, R. V. P.; MORELLO, D.; ROSATELI, P. A.; FILIPECKI, L. C. Bacteriemia após exodontia unitária, empregando dois métodos de anti-sepsia intrabucal. Pesq Odont Bras, v. 14, n. 1, p. 19-24, jan./mar. 2000.

trabalho, ou até mesmo, da intensidade de uso de antibióticos nas diversas áreas geográficas, uma vez que, o antibiograma representa um estado dinâmico e indica os hábitos de antibioticoterapia seguidos em certa época, em certa área geográfica (SOLÉ-VERNIN; UTHIDA-TANAKA ${ }^{24}, 1969$ ).

\section{CONCLUSÕES}

A análise dos resultados permite concluir que a freqüência de bacteriemia pós-exodontia com o emprego do método 1 ou 2 de anti-sepsia foi elevada, situando-se em 68,8 e 70,6\%, respectivamente. Nas hemoculturas pós-exodontias precedidas de anti-sepsia, empregando-se o método 1 ou 2, prevaleceram microrganismos anaeróbios. A amo- xicilina e o cloranfenicol foram eficientes contra os microrganismos isolados das hemoculturas pós-exodontias.

\section{AGRADECIMENTOS}

Nossos sinceros agradecimentos às funcionárias Benedita Panari, Floripes Carvalho, Maraísa Verri, Maria Aparecida Joanin e ao estagiário Rodrigo Fernando André, do Departamento de Ciências de Saúde da Faculdade de Ciências Farmacêuticas de Ribeirão Preto - USP.

O presente projeto teve apoio financeiro do CNPq e da FAPESP (processos 520824/94 e 94/0703-9).

ROCHA BARROS, V. M.; ITO, I. Y.; AZEVEDO, R. V. P.; MORELLO, D.; ROSATELI, P. A.; FILIPECKI, L. C. Bacteremia following dental extraction and two methods of intra-oral antisepsis. Pesq Odont Bras, v. 14, n. 1, p. 19-24, jan./mar. 2000.

The study was designed both to evaluate the frequency of bacteremia following teeth extraction and to identify the microorganisms isolated in post-extraction bacteremia. In addition, the antibiotic susceptibility of the microorganisms was tested. For this, 26 patients were divided into two groups according to the treatment they had received: 1) clorhexidine $(0.12 \%)$ mouthwash followed by rubbing the teeth surfaces using the same solution; 2$)$ two mouthrinses with $15 \mathrm{ml}$ of cetylpyridinium chloride for one minute, interposed by rubbing the teeth surfaces with hydrogen peroxide (3\%). Regardless of the utilized antisepsis method, the frequency of post-extraction bacteremia was high. Anaerobic microorganisms were predominant in post-extraction bloodcultures, presenting susceptibility to amoxicillin and to chloramphenicol.

UNITERMS: Mouthwashes; Antibiotics.

\section{REFERÊNCIAS BIBLIOGRÁFICAS}

1. ANGRIST, A. A.; OKA, M.; NAKAO, K. Vegetative endocarditis. Pathol Annu, v. 2, p. 155-212, 1967.

2. BALTCH, A. L.; PRESMAN, H. L.; HAMMER, M. C.; SUTPHEN, N. C.; SMITH, R. P.; SHAYEGANI, M. Bacteremia following dental extractions in patients with and without penicillin prophylaxis. Am J Med Sci, v. 283, p. $129-140,1982$.

3. BEIGHTON, D.; CARR, A. D.; OPPENHEIM, B. A. Identification of viridans streptococci associated with bacteremia in neutropenic cancer patients. J Clin Microbiol, v. 40, p. 202-204, 1994.

4. BEIGHTON, D.; HARDIE, J. M.; WHILEY, R. A. A scheme for the identification of viridans streptococci. J Med Microbiol, v. 35, p. 376-372, 1991.

5. BENDER, I. B.; BARKAN, M. J. Dental bacteremia and its relation to bacterial endocarditis: preventive measures. Compend Contin Educ Dent, v. 10, p. 472-482, 1989.

6. BLUM, R. A.; RODVOLD, K. A. Recognition and importance of Staphylococcus epidermidis infection. Clin Pharm, v. 6, p. 464-475, 1987.

7. DAJANI, A. S.; BISNO, A. L.; CHUNG, K. J.; DURACK, D. T.; FREED, M.; GERBER, M. A.; KARCHMER, A. W.;
MILLARD, H. D.; RACHIMTOOLA, S.; SHULMAN, S. T.; WATANAKU-NAKORN, C.; CAUBERT, K. A. Prevention of bacterial endocarditis: recommendation by the American Heart Association. J Am Med Assoc, v. 264, p. 2919-2922, 1990.

8. EVALDSON, G.; HEIMDAHL, A.; KAGER, L.; NORD, C. E. The normal human anaerobic microflora. Scand $\mathbf{J}$ Infect Dis, v. 35, p. 9-15, 1982. Suppl.

9. FURINI, C. J.; FRIEDRICH, C. L.; GRESSLER, J. F.; BASSO, M. A. R.; RODRIGUES, A. L.; POERNER, S. C. Endocardite infecciosa. Análise de 28 episódios. Saúde UFSM., v. 19, p. 47-54, 1993.

10. GOULD, K.; RAMIREZ-RONDA, C. H.; HOLMES, R.; SANFORD, J. P. Adherence of bacteria to heart valves in vitro. J Clin Invest, v. 56, p. 1364-1370, 1975.

11. HALL, G.; HEDSTRÖM, S. A.; HEIMDAHL, A.; NORD, C. E. Prophylactic administration of penicillins for endocarditis does not reduce the incidence of postextraction bacteremia. Clin Infect Dis, v. 17, p. 188-194, 1993.

12. HEIMDAHL, H.; HALL, G.; HEDBERG, M.; SANDBERG, H.; SÖDER, P. O.; TUNER, K.; NORD, C. E. Detection and quantitation by lysis-filtration of bacteremia after different oral surgical procedures. J Clin Microbiol, v. 28, p. 2205-2209, 1990. 
ROCHA BARROS, V. M.; ITO, I. Y.; AZEVEDO, R. V. P.; MORELLO, D.; ROSATELI, P. A.; FILIPECKI, L. C. Bacteriemia após exodontia unitária, empregando dois métodos de anti-sepsia intrabucal. Pesq Odont Bras, v. 14, n. 1, p. 19-24, jan./mar. 2000.

13. HILLIER, S. L.; MONCLA, B. J. Peptostreptococcus, Propionibacterium, Eubacterium, and other nonsporeforming anaerobic gram-positive bacteria. In: MURRAY P.R. (ed.) Manual of clinical microbiology. 6th ed. Washington DC: ASM Press, 1995. p. 587-602.

14. JASPER, M. T.; LITTLE, J. W. Infective endocarditis: a review and update. Oral Surg, v. 57, p. 606-615, 1984.

15. LEPORT, C. Prophylaxie de l'endocardite infectieuse. Ann Chir, v. 46, p. 778-782, 1992.

16. LEVINER, E.; TZUKERT, A.; WOLF, A.; SHAULI, S.; SELA, M. N. Hospital personnel with penicillin-resistant Streptococcus viridans; a case for special consideration in the prevention of bacterial endocarditis. Oral Surg, v. 58, p. 394-396, 1984.

17. MacFARLANE, T. W.; FERGUSON, M. M.; MULGREW, C. J. Pos-extraction bacteraemia: role of antiseptics and antibiotics. Br Dent J, v. 156, p. 179-181, 1984.

18. McGOWAN, D. A. Endodontics and infective endocarditis. Int Endod J, v. 15, p. 127-131, 1982.

19. MOORE, E. C.; RANNEY, R. R.; HOLDEMAN, I. V. Sublingual microflora in periodontal disease: cultural studies. In: GENCO, R. J.; MERGENHAGEN, S. Host parasite interactions in periodontal diseases. Washington, DC : American Society for Microbiology, 1982. p. 13-26.

20. NORD, C. E.; HEIMDAHL, A. Cardiovascular infections: bacterial endocarditis of oral origin. Pathogenesis and prophylaxis. J Clin Periodontol, v. 17, p. 494-496, 1990.

21. RUOFF, K. L. Streptococcus. In: MURRAY, P. R. (ed.) Manual of clinical microbiology. 6th ed. Washington DC : ASM Press, 1995. p. 299-307.

22. SHANSON, D. C.; CANNOM, P.; WILKS, M. Amoxiycillin compared with penicillin $\mathrm{V}$ for the prophylaxis of dental bacteremia. J Antimicrob Chemother, v. 4, p. 431-436, 1978.

23. SIMMONS, N. A.; CAWSON, R. A.; EYKYN, S. J.; LAMBERT, H. P.; LITTLER, W. A.; McGOWAN, D. A.; OAKLEY, C. M.; SHANSON, D. C. Antibiotic prophylaxis of infective endocarditis recomendations from the working party of the British Society for Antimicrobial Chemotherapy. Lancet, v. 335, p. 88-89, 1990.

24. SOLÉ-VERNIN, C.; UTHIDA-TANAKA, A. M. A prova de Moore conjugada ao antibiograma na identificação de amostras hospitalares e não hospitalares de Staphylococcus aureus. Hospital, v. 75, p. 2043-2086, 1969.

25. EXLER, H. H.; DOERN, G. V. Susceptibility testing of anaerobic bacteria. In: MURRAY, P.R. (ed.) Manual of clinical microbiology. 6th ed. Washington DC : ASM Press, 1995. p. 1350-1355.

26. WOODS, G. L.; WASHINGTON, J. A. Antibacterial susceptibility tests: dilution and disk diffusion methods. In: MURRAY, P. R. (ed.) Manual of clinical microbiology. 6th ed. Washington: ASM Press, 1995. p.1327-1341.

Recebido para publicação em 08/09/99

Enviado para reformulação em 10/11/99 Aceito para publicação 09/02/00 